\title{
A Prospective Observational Study on the Association of the Renal Disease with the use of Proton Pump Inhibitors in a Tertiary Care Hospital
}

\author{
Gulipalli Sowjanya, Katta Amulya, Rama Priyanka, Karnati Gayathri, B. Rajesh, Ganpisetti Ramesh*, \\ P. Srinivasababu \\ Department of Pharmacy Practice, Vignan Pharmacy College, Vadlamudi, Guntur, Andhra Pradesh, INDIA.
}

\begin{abstract}
Aim: To find out the association of the renal disease with the use of proton pump inhibitors. Objective: To quantify if an association between the renal disease with the use of PPIs. Method: This is a prospective observational based study conducted in 266 patients from the gastroenterology department. The patients were selected based on inclusion and exclusion criteria. Patients who are diagnosed with acid related disease such as Gastro Esophageal Reflux Disease (GERD), Peptic ulcers including gastric ulcers, duodenal ulcers and other acid related disease, Patients with Age between 45-65 years of both genders, Patients who are willing to participate in the study, Patient with Once Daily (OD) and twice daily (BID) prescribed PPIs, Patients who are not receiving on treatment of PPIs and Patients with the chronic use (Duration of PPI treatment before presentation between 2 weeks and 6 months) of PPIs are included in the study. Patients with co-morbidities were at greater risk of kidney disease, Patients with any kidney infections, Patients prescribed with any nephrotoxic drugs, pregnant women and Paediatric population are excluded from the study. In this study we assessed for both patients who were taking PPIs and who were not taking PPIs. These patients was, follow up for three months at an interval of 15 days review was carried out. Based on these laboratory parameters like serum creatinine, Blood Urea Nitrogen (BUN), Glomerular Filtration Rate (GFR), serum electrolytes levels whether PPIs are associated in developing renal diseases can be determined. For the purpose of this analysis we compared renal function test at baseline and after a follow up for 3 months. Results: Users of PPIs compared with nonusers of PPIs, had an increased risk for double levels of creatinine, Blood Urea Nitrogen (BUN) and a decrease in Glomerular Filtration Rate (GFR). Both PPls users and non-users were examined using chi-square test. All analyses are performed by using graph pad prism (version 7) and the results were considered statistically significant when $p$ values were $<0.05$, Odds ratio $\mathrm{OR}=7.452(95 \% \mathrm{Cl}=1.238$ to 84.71$)$ and Relative risk $=7(95 \% \mathrm{Cl}=1.155$ to 43.25$)$ this shows PPIs are associated in causing renal disease. Conclusion: Use of proton pump inhibitors is associated with increased risk of development of renal disease. Hence, it is necessary that the awareness of physicians and pharmacist is increased to the recognition of the patient complaints and the clinical manifestations.
\end{abstract}

Key words: Proton pump inhibitors, Renal disease, Glomerular filteration rate, Blood urea nitrogen.

\section{INTRODUCTION}

Proton Pump Inhibitors (PPIs) are among the most widely prescribing medications in the world in both prescription and Overthe-counter (OTC) sales ${ }^{1}$ and it has been estimated that between $25 \%$ and $70 \%$ of these prescriptions have no appropriate indication. ${ }^{2}$ The duration of use frequently extends beyond recommended guidelines. ${ }^{3,4}$ There is also trend towards PPI use in infants and children. ${ }^{5,6}$ Since, they have been introduced into clinical practice in late 1980s, Proton Pump Inhibitor (PPI) utilization has increased rapidly ${ }^{7}$ and as recently as 1970s, surgery was a primary option for the management of peptic ulcer disease. The advent of Proton Pump Inhibitors (PPIs) (Table 1) and histamine receptor antagonist in the 1970s and 1980s, respectively, largely supplanted surgery and revolutionized the treatment of peptic ulcer disease. Today they are the mainstay therapy in Gastro Oesophageal Reflux Disease (GERD), gastritis and duodenal or gastric ulcers due to excessive acid production. ${ }^{8}$
DOI: 10.5530/ijopp.12.2.22

Address for correspondence: Ramesh Ganpisetti, Department of Pharmacy Practice, Vignan Pharmacy College, Vadlamudi, Guntur-522213, Andhra Pradesh, INDIA.

Phone no: +918686473659

Email Id: ramiganpisetti@gmail. com

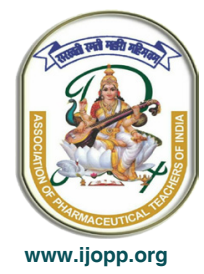




\section{All PPIs possess a common mechanism of action for reducing parietal cell acid}

All PPIs possess a common mechanism of action for reducing parietal cell acid production by blocking gastric hydrogen potassium ATPase. ' Several studies have shown an association between long term prescription of PPIs and the appearance of adverse effects such as increased hazards of cardiovascular disease, osteoporosis, community acquired pneumonia, gastric carcinoids, Hypomagnesemia, nutritional deficiency, Vitamin $\mathrm{B}_{12}$ deficiency and also been linked to increased risk of enteric infections most notably clostridium difficile-associated disease. ${ }^{10,11}$ Chronic use of PPIs have been also associated with an increased risk of renal disease or renal failure. ${ }^{12}$ The mechanism of the association between PPIs use and renal disease were not clear yet. The proposed mechanism could be through Acute Interstitial Nephritis (AIN). Most AKI events were identified specifically in the form of acute interstitial nephritis which was suggested to have an association with PPIs exposure by multiple studies. ${ }^{13}$

PPI induced AIN might be a cell mediated idiosyncratic immune response, a class effect as all PPIs could cause AIN. ${ }^{14,15}$ Laboratory abnormalities were more consistently present in PPI-induced renal disease, with elevated serum creatinine, Blood Urea Nitrogen (BUN), Glomerular Filtration Rate (GFR). ${ }^{15,16}$

In general, most patients with acute renal failure are assumed to have acute tubular necrosis. ${ }^{17}$ It is not surprising that Acute Interstitial Nephritis (AIN) secondary to PPI use may also undetected due to several reasons. ${ }^{18}$

1. Awareness that PPIs can cause AIN may not be spread

2. Typical features of hypersensitivity reaction are present in only a minority of cases.

3. Patients with undiagnosed Acute Kidney Injury (AKI).

However, data is lacking on the association renal disease with the use of the Proton Pump Inhibitors (PPIs). Hence, we investigate the relationship of PPI use and the development of renal disease.

\section{METHODOLOGY}

\section{Data source and study design}

The data was collected in a specially designed proforma for collecting patient details. The information was directly collected in both inpatients and outpatient's prescription. We used the various laboratory parameters (Haemoglobin, serum creatinine, Blood Urea Nitrogen (BUN), Glomerular Filtration Rate (GFR) and urine analysis) suiting to our study. It is a Prospective Observational based study will be conducted in Gastroenterology Department at a tertiary care hospital was carried out for a duration of six months.

\section{Study population}

We included patients with age between 45-65 years of both genders, subjects with Gastro Oesophageal Reflux Disease (GERD), Peptic ulcers including gastric ulcers, duodenal ulcers and other acid related disease, patients who are willing to participate in the study, patient with Once Daily (OD) and twice daily (BID) prescribed PPIs, patients who are not receiving on treatment of PPIs, patients with the chronic use of PPIs (Duration of PPI treatment between 2 weeks and 6 months before presentation).

The only exclusion criteria considered patient with co-morbidities were at greater risk of kidney disease, patients with any kidney infections, patients prescribed with any nephrotoxic drugs, pregnant women, paediatric population (Table 2).

\section{Plan of work}

The study methodology was determined and protocol was prepared and ethical committee permission was taken. Study subjects are selected, with Gastro Oesophageal Reflux Disease (GERD), Peptic ulcers including gastric ulcers, duodenal ulcers and other acid related disease. They were divided into 2 groups: Group A: Patients with PPI users, Group B: Patients with PPI non-users. They were Follow up for every 15 days up to 3 months. Development of type of renal disease can be determining

\begin{tabular}{|c|c|c|}
\hline $\begin{array}{l}\text { Proton pump } \\
\text { inhibitors (PPI) }\end{array}$ & $\begin{array}{l}\text { Standard dose } \\
\text { (healing) } \\
\text { (once daily) }\end{array}$ & $\begin{array}{c}\text { Low dose } \\
\text { (maintenance) } \\
\text { (once daily) }\end{array}$ \\
\hline $\begin{array}{c}\text { Omeprazole } \\
\text { (LOSEC)-Capsule }\end{array}$ & $20 \mathrm{mg}^{*}$ & $10 \mathrm{mg}^{*}$ \\
\hline $\begin{array}{l}\text { Esomeprazole } \\
\text { (NEXIUM)-Tablet }\end{array}$ & $20^{\mathrm{a}}$ or $40^{\mathrm{b}} \mathrm{mg}$ & $20 \mathrm{mg}$ \\
\hline $\begin{array}{c}\text { Lansoprazole } \\
\text { (PREVACID)-Capsule }\end{array}$ & $30 \mathrm{mg}^{*}$ & $15 \mathrm{mg}^{*}$ \\
\hline $\begin{array}{l}\text { Dexlansoprazole } \\
\text { (DEXILANT)-Tablet }\end{array}$ & $30^{\mathrm{c}}$ or $40^{\mathrm{d}} \mathrm{mg}$ & $30 \mathrm{mg}$ \\
\hline $\begin{array}{c}\text { Pantoprazole } \\
\text { (PANTOLAC, TECTA)- } \\
\text { Tablet }\end{array}$ & $40 \mathrm{mg}$ & $20 \mathrm{mg}$ \\
\hline $\begin{array}{c}\text { Rabeprazole } \\
\text { (PARIET)-Tablet }\end{array}$ & $20 \mathrm{mg}$ & $10 \mathrm{mg}$ \\
\hline
\end{tabular}

Indian Journal of Pharmacy Practice, Vol 12, Issue 2, Apr-Jun, 2019 


\section{Table 2: Pharmacokinetics of orally available proton pump inhibitors.}

\begin{tabular}{ccccc} 
Characteristic & Omeprazole & Lansoprazole & Rabeprazole & Pantoprazole \\
\hline Bioavailability (\%) & $30-40$ & $80-85$ & 52 & 77 \\
Time to peak plasma concentration (h) & $0.5-3.5$ & 1.7 & $1.0-2.0$ & $1.1-3.1$ \\
Half-life (h) & & & & \\
Protein binding & $0.5-1.0$ & $1.3-1.7$ & $1.0-2.0$ & $1.0-1.9$ \\
Urinary excretion of oral dose (\%) & 95 & 97 & 96 & 98 \\
& 77 & $14-23$ & $30-35$ & $71-80$
\end{tabular}

by using laboratory tests like serum creatinine, Blood Urea Nitrogen (BUN), Glomerular Filtration Rate (GFR) and Serum electrolytes. Collection and tabulation of data by using statistical methods. All participants were followed up through a telephone survey and a review of community hospital. The data of the patients attending the gastroenterology ward, during the period, were collected during ward rounds and were recorded in an online data storage (Google forms).

\section{Data collection}

The notes of those patients with a diagnosis of any acid related disease were reviewed for the circumstances of their presentation, medical history, investigations, treatment and outcome. Specific details noted for each patient were: age at presentation, gender, all medications (with duration of treatment) and investigations including haemoglobin, serum creatinine, Blood Urea Nitrogen (BUN), Glomerular Filtration Rate (GFR) and urine analysis. Renal function tests (serum creatinine, blood urea nitrogen and glomerular filtration rate) measured at 3- and 6-months following diagnosis at an interval of 15 days review for both PPI users and PPI non users and at the end of the 6 months study period.

\section{Statistical analysis}

The Chi-Square test was used and all statistical calculations were carried out with Graph prism pad 7 version.

\section{RESULTS}

A total number of 266 patients are recruited in the study, among them 47 individuals were excluded because they had co-morbidities were prone to greater risk of kidney infections and 11 individuals were excluded because they are refused to participate. Additional 8 individuals were excluded because of lack of renal function tests (serum creatinine, Blood Urea Nitrogen (BUN) and Glomerular Filtration Rate (GFR)) during follow up their follow-up. In that 100 Study subjects are selected, with Gastro Oesophageal Reflux Disease (GERD), Peptic ulcers including gastric ulcers, duodenal ulcers and other acid related disease who are using Once Daily (OD) and twice daily (BID) prescribed PPIs. Another 100 study subjects are selected who are not using any PPI and nephrotoxic drugs. A three months follow up at an interval of 15 days review was carried out for both PPI users and PPI non-users. Based on these laboratory parameters like serum creatinine, Blood Urea Nitrogen (BUN), Glomerular Filtration Rate (GFR), serum electrolytes levels whether PPIs are associated in developing renal diseases can be determined. Kidney disease cases and controls with PPIs and without PPIs were examined using chi-square test. All analyses are performed by using graph pad prism (version 7) and the results were considered statistically significant when $p$ values were $<0.05$, Odds ratio $(\mathrm{OR})=7.452(95 \% \mathrm{CI}=1.238$ to 84.71$)$ and Relative risk $(\mathrm{RR})=7(95 \% \mathrm{CI}=1.155$ to 43.25$)$ this shows PPIs are associated in causing renal disease.

\section{PPI Users VS PPI Non-Users}

Data analysed in this prospective observational study were examined using the Chi-square test.

From the current data PPI users, out of 100 individuals, 7 individuals shows PPIs are associated in developing renal disease and remaining 93 individuals doesn't develop any renal disease. In PPI non-users, out of 100 individuals 1 shows kidney disease due to other risk factors that are involved in causing kidney disease and remaining 99 individuals doesn't develop any renal disease.

\section{Study Population}

A total of 266 patients were presented to the gastroenterology department out of which 208 patients met inclusion and exclusion criteria and agreed to participate in the study. Additionally, 8 patients missed their follow-up. In this study 100 [50\%] individuals are of PPI users and $100[50 \%]$ individuals are of PPI non-users.

\section{Age Distribution}

When categorized age wise, maximum number of patients $57.14 \%$ from the age group of 56-60 years are more prone to renal disease associated with the use of proton pump inhibitors followed by $25 \%$ from the age group of 61-65 years and lower number of patients 12.5\% from the age group of 51-55 years. 


\section{Gender Distribution}

In our study population out of 7 effected patients, 5 patients (71\%) were male and 2 patients (29\%) are females, males are more prone to renal disease associated with the use of proton pump inhibitors than female's patients.

\section{Serum Creatinine Levels at Baseline and at the end of PPI users}

Out of 100 individuals, 7 individuals shows the creatinine level is normal at baseline and after a period of three months follow up these 7 individuals shows a significant increase in creatinine level at the end of the study. This shows PPIs are associated in developing renal diseases by increasing serum creatinine levels (Table 3).

\section{Blood Urea Nitrogen (BUN) levels at baseline and at the end of PPI users}

The study shows that out of 100 individuals, 7 individuals shows the BUN level is normal at baseline and after a period of three months follow up these 7 individuals shows a significant increase in BUN level at the end of the study. This shows PPIs are associated in developing renal diseases by increasing BUN levels.

\section{Glomerular Filtration Rate (GFR) levels at baseline and at the end of PPI users}

This study shows that out of 100 individuals, 7 individuals shows the GFR level is normal at baseline and after a period of three months follow up these 7 individuals shows a significant decrease in GFR level at the end of the study. This shows PPIs are associated in developing renal diseases by decreasing GFR levels.

\section{Serum Creatinine levels at baseline and at the end of PPI non-users}

In patients with PPI non-users out of 100 individuals 1 individual shows the creatinine level is normal at baseline and after a period of three months follow up 1 individual shows a significant increase in creatinine level at the end of the study. This shows there may be some other risk factors in causing renal disease by increasing serum creatinine levels (Table 4).

\section{Blood Urea Nitrogen (BUN) levels at baseline and at the end of PPI non-users}

In patients with PPI non-users out of 100 individuals 7 individual shows the BUN level is normal at baseline and after a period of three months follow up 1 individual shows a significant increase in BUN level at the end of the

Table 3: Details of those patients associated with renal disease with the use of proton pump inhibitors (PPIS).

\begin{tabular}{|c|c|c|c|c|c|c|c|c|}
\hline $\begin{array}{l}\text { Age/ } \\
\text { Gender }\end{array}$ & $\begin{array}{c}\text { Creatinine } \\
\text { at Base line }\end{array}$ & $\begin{array}{l}\text { BUN } \\
\text { at } \\
\text { Base } \\
\text { line }\end{array}$ & $\begin{array}{l}\text { GFR } \\
\text { at } \\
\text { Base } \\
\text { line }\end{array}$ & Medications & Diagnosis & $\begin{array}{c}\text { Follow-up } \\
\text { (3months) } \\
\text { Creatinine at } \\
\text { END }\end{array}$ & $\begin{array}{l}\text { BUN } \\
\text { at END }\end{array}$ & $\begin{array}{l}\text { GFR } \\
\text { at END }\end{array}$ \\
\hline $60 / \mathrm{M}$ & 0.9 & 20 & 93 & $\begin{array}{l}\text { Tab. Cefpodoxime } \\
\text { Cap. Pantoprazole } \\
\text { Tab. Paracetmol } \\
\text { Syr. Lactulose }\end{array}$ & $\begin{array}{l}\text { acute interstial } \\
\text { pancreatitis and } \\
\text { cholelithiasis }\end{array}$ & 1.3 & 25 & 59 \\
\hline $65 / M$ & 0.8 & 18 & 94 & $\begin{array}{c}\text { Tab. Pantoprazole } \\
\text { Vit-B Complex } \\
\text { macrogol }\end{array}$ & GERD & 1.5 & 23.5 & 48 \\
\hline $56 / F$ & 0.9 & 16 & 95 & $\begin{array}{l}\text { Tab. Pantoprazole } \\
\text { Syr. Sucralfate }\end{array}$ & Peptic ulcers & 1.2 & 28 & 67 \\
\hline $63 / \mathrm{M}$ & 0.9 & 20 & 91 & $\begin{array}{l}\text { Tab. Iron } \\
\text { Tab. Esemeprazole } \\
\text { Sry. Sucralfate } \\
\text { ursodeoxycholicacid }\end{array}$ & Duodenal ulcers & 1.1 & 28 & 54 \\
\hline $55 / F$ & 0.8 & 17 & 101 & $\begin{array}{l}\text { Sry. Sucralfate } \\
\text { B-complex forte } \\
\text { Sry. Lactulose } \\
\text { Tab. Pantoprazole }\end{array}$ & & 1.3 & 30 & 61 \\
\hline $60 / \mathrm{M}$ & 0.7 & 20 & 103 & $\begin{array}{l}\text { Sry. Sucralfate } \\
\text { B-complex forte } \\
\text { Sry. Lactulose } \\
\text { Tab.pantoprazole }\end{array}$ & Gastric ulcers & 1.2 & 22.5 & 65 \\
\hline $56 / \mathrm{M}$ & 0.9 & 20 & 95 & $\begin{array}{l}\text { Tab. Pantoprazole } \\
\text { Ondansetron, } \\
\text { Syr. Sucralfate }\end{array}$ & GERD & 1.2 & 25.5 & 67 \\
\hline
\end{tabular}


Table 4: Details of those patients associated with renal disease without the use of proton pump inhibitors (PPIS).

\begin{tabular}{|c|c|c|c|c|c|c|c|c|}
\hline $\begin{array}{l}\text { Agel } \\
\text { Gender }\end{array}$ & $\begin{array}{l}\text { Creatinine } \\
\text { at Baseline }\end{array}$ & $\begin{array}{c}\text { BUN at } \\
\text { Base } \\
\text { line }\end{array}$ & $\begin{array}{c}\text { GFR } \\
\text { at Baseline }\end{array}$ & Medications & Diagnosis & $\begin{array}{l}\text { Follow-up(3months) } \\
\text { Creatinine at END }\end{array}$ & $\begin{array}{l}\text { BUN } \\
\text { at END }\end{array}$ & $\begin{array}{l}\text { GFR } \\
\text { at END }\end{array}$ \\
\hline $65 / M$ & 0.6 & 16 & 106 & $\begin{array}{c}\text { Syp. sucralfate } \\
\text { Vit-B Complex } \\
\text { Macrogol }\end{array}$ & Gastroentritis & 1.3 & 25 & 57 \\
\hline
\end{tabular}

study. This shows there may be some other risk factors in causing renal disease by increasing BUN levels.

\section{Glomerular Filtration Rate (GFR) levels at baseline and at the end of PPI non-users}

In patients with PPI non-users out of 100 individuals 1 individual shows the GFR level is normal at baseline and after a period of three months follow up 1 individual shows a significant decrease in GFR level at the end of the study. This shows there may be some other risk factors in causing renal disease by decreasing GFR levels.

\section{Association of renal disease with PPI users and PPI non-users}

From the current data PPI users, out of 100 individuals, 7 individuals shows chronic use of PPIs are associated in developing renal disease. In PPI non-users, out of 100 individuals 1 individual shows renal disease due to other risk factors that are involved in causing kidney disease.

\section{DISCUSSION}

In this prospective observational study, we demonstrate that current use of PPIs was associated with a significant increase in serum creatinine there by it leads to kidney disease, which was not associated with Histamine type 2 Receptor Antagonist (H2RA) and other PPI non users. In our study population maximum number of patients $(57.14 \%)$ from the age group of $56-60$ years are more prone to renal disease associated with the use of proton pump inhibitors. Males are more prone to renal disease associated with the use of proton pump inhibitors than female patients. The biological mechanisms supporting the observed association of PPI with renal outcomes are unclear.

\section{CONCLUSION}

In this study, we found that long-term use of proton pump inhibitors is associated with increased risk of developing renal disease. Although cause and effect cannot be determined with an observational study, with the large number of patients being treated with proton pump inhibitors, healthcare providers need to be cautious in prescribing these drugs because of the potential side effects.

We found that PPI use was an independent risk factor for renal disease. Several questions remain unanswered. If PPIs do not have a direct causal role in the development of renal diseases, what could be the exact mechanism of renal diseases due to PPI use?

Further research is required to investigate whether PPI use itself causes kidney damage. Hence, it is necessary to make an awareness to physicians and pharmacists, hence clinicians should monitor patients and stop the indiscriminate use of these drugs.

\section{ACKNOWLEDGEMENT}

We would like to bring to light those who have helped us in completion of this work without which this work would not have reached its destination.

\section{CONFLICT OF INTEREST}

The authors declare no conflict of interest.

\section{ABBREVIATIONS}

AIN: Acute Interstitial Nephritis; AKI: Acute Kidney Injury; ARF: Acute Renal Failure; ATN: Acute Tubular Necrosis; ATPase: Adenosine Tri Phosphatase; BID: Bis In Die; BUN: Blood Urea Nitrogen; CI: Confidence Interval; CKD: Chronic Kidney Disease; ESRD: End Stage Renal Disease; GERD: Gastro Esophageal Reflux Disease; GFR: Glomerular Filtration Rate; H2RA: Histamine type 2 Receptor Antagonist; OD: Once Daily; OR: Odds Ratio; OTC: Over-The- Counter; PPIs: Proton Pump Inhibitors; RR: Relative Risk.

\section{SUMMARY}

In this study, we found that long-term use of proton 
pump inhibitors is associated with increased risk of developing renal disease. Although cause and effect cannot be determined with an observational study, with the large number of patients being treated with proton pump inhibitors, healthcare providers need to be cautious in prescribing these drugs because of the potential side effects. We found that PPI use was an independent risk factor for renal disease.

\section{REFERENCES}

1. Forgacs I, Loganayagam A. Overprescribing proton pump inhibitors. BMJ. 2008;336(7634):2-3. [PubMed: 18174564]

2. Grant K, Al-Adhami N, Tordoff J, Livesey J, Barbezat G, Reith D. Continuation of proton pump inhibitors from hospital to community. Pharm World Sci. 2006;28(4):189-93. [PubMed: 17066244]

3. Wilhelm SM, Rjater RG, Kale-Pradhan PB. Perils and pitfalls of long-term effects of proton pump inhibitors. Expert Rev Clin Pharmacol. 2013;6(4):443-51. [PubMed: 23927671].

4. Barron JJ, Tan H, Spalding J, Bakst AW, Singer J. Proton pump inhibitor utilization patterns in infants. J Pediatr Gastroenterol Nutr. 2007;45(4):421-7. [PubMed: 18030207].

5. DeBruyne P, Christiaens T, Vander SR, Winckel MV. Changes in prescription patterns of acid-suppressant medications by Belgian pediatricians: Analysis of the national database, [1997- 2009]. J Pediatr Gastroenterol Nutr. 2014;58(2):220-5. [PubMed: 24464148].

6. Grace NE. American College of Rheumatology. Guidelines for the management of rheumatoid arthritis: 2002 update. J Am Acad Nurse Pract. 2002;14(10):432-7.
7. Robinson M, Horn J. Clinical pharmacology of proton pump inhibitors: What the practising physician needs to know. Drugs. 2003;63(24):2739-54.

8. Playford RJ, Podas T, Modlin I. Pantoprazole, Prout and the proton pump. Hosp Med. 1999;60(7):500-4.

9. Bateman DN, Colin-Jones D, Hartz S, et al. Mortality study of 18,000 patients treated with omeprazole. Gut. 2003;52(7):942-6.

10. Heidelbaugh J, Kim AH, Chang R, Walker PC. Overutilization of proton-pump inhibitors: what the clinician needs to know. Therapy Adv Gastroenterol. 2012;5(4):219-32.

11. U.S. Food and Drug Administration (FDA). FDA drug safety podcast for healthcare professionals: low magnesium levels can be associated with longterm use of Proton Pump Inhibitors drugs (PPIs). 2009.

12. O'Mahony D, O'Sullivan D, Byrne $S$, et al. STOPP/START criteria for potentially inappropriate prescribing in older people: Version 2. Age Ageing. 2015;44(2):213-8.

13. Abu-Sneineh A, Tam W, Schoeman M, et al. The effects of high dose esomeprazole on gastric and oesophageal acid exposure and molecular markers in Barrett's oesophagus. Aliment Pharmacol Ther. 2010;32(8):1023-30.

14. Langtry HD, Wilde MI. Lansoprazole: An update of its pharmacological properties and clinical efficacy in the management of acidrelated disorders. Drugs. 1997; $54: 473500$.

15. Pantoprazole (Protonix). Package Insert. Philadelphia, PA: Wyeth Ayerst. 2000. Available from: http://labeling.pfizer.com/ ShowLabeling. aspx?id=135.

16. Singer S, Parry RG, Deodhar HA, Barnes JN. Acute interstitial nephritis, omeprazole and antineutrophil cytoplasmic antibodies [letter]. Clin Nephrol. 1994;42(4):280.

17. Omeprazole (Prilosec). Package Insert. Wayne, PA: Astra Pharmaceuticals. 1998. Available from:http://www.azpicentral.com/ prilosec/prilosec. pdf\#page=1.

18. Maggio M, Corsonello A, Ceda GP, Cattabiani C, Lauretani F, ButtoV, et al. Proton Pump Inhibitors and Risk of 1-Year Mortality and hospitalization in older patients discharged from acute care hospitals. JAMA Intern Med. 2013;173(7):518-23. 